\title{
O BRINQUEDO NO HOSPITAL: UMA ANÁLISE DA PRODUÇÃO ACADÊMICA DOS ENFERMEIROS BRASILEIROS
}

\author{
The Toy in the Hospital: \\ An Analysis of the Brazilian Nurses' Academic Production \\ El J uguete en el Hospital: \\ Un Análisis de la Producción Académica de los Enfermeros Brasileños
}

Tânia Maria Coelho Leite

Antonieta Keiko Kakuda Shimo

\begin{abstract}
Resumo
Este estudo teve como objetivo analisar o conteúdo das teses e dissertações de enfermeiros brasileiros sobre a utilização do brinquedo no hospital. 0 levantamento dos dados foi realizado por meio de uma busca no Portal CAPES, CEPEn, IBICT e consulta às referências dos trabalhos, que foram analisados qualitativamente. Os objetivos mais freqüentemente encontrados referem-se à vivência da criança durante a hospitalização, ao significado e importância do brinquedo e dificuldades para sua implantação. 0 brinquedo foi utilizado com maior freqüência no pré e pós-operatório. A análise dos resultados obtidos nos trabalhos pautou-se nos efeitos do brinquedo sobre as crianças. Ficou evidente que, para os enfermeiros, o brinquedo é ferramenta indispensável no cuidado à criança. Portanto, recomenda-se que a prática do brinquedo / brinquedo terapêutico seja utilizada no plano de assistência de enfermagem pediátrica.
\end{abstract}

Palavras-chave: Jogos e Brinquedos. Enfermagem Pediátrica. Criança. Recreação.

\section{Abstract}

The purpose of this study was to analyze the thesis and dissertations produced by Brazilian nursing personnel on the use of toys in hospitals. A data survey was conducted using the CAPES, CEPEn and IBICT Websites and the studies references were consulted and qualitatively analyzed. The results of this study showed that the objectives frequently referred to the child's experiences during hospitalization, the significance and importance of the toy and the difficulty encountered in its implantation. The use of the toy was used more often before and after the operative periods and these analysis were based on the effects of the toy on children. It became evident to the nursing personnel that the toy is an indispensable tool for childcare. Therefore, we recommended that both the therapeutic toy and the practice toy be used in the nursing pediatric care plan.

\section{Keywords:}

Games and Toys. Pediatric Nursing. Chile. Recreation.

\section{Resumen}

Este estudio tuvo como objetivo analizar el contenido de las tesis y disertaciones de enfermeros brasileños sobre la utilización del juguete en el hospital. Los datos fueron levantados a traves de una búsqueda en el Portal CAPES, CEPEn, IBICT, consultando las referencias de los trabajos y analizándolos de manera cualitativa. Los objetivos encontrados con más frecuencia se refieren a la vivencia del niño durante la hospitalización, al significado y a la importancia del juguete y a las dificultades para implantar su presencia en el ámbito hospitalar. El juguete fue usado con más frecuencia en el pré y en el post-operatorio. El análisis de los resultados obtenidos en los trabajos fué pautado en el efecto que los juguetes tienen sobre los niños. Quedó evidente que para los enfermeros, el juguete es una herramienta indispensable en el cuidado de los niños. Por lo tanto, recomiendase que la práctica del juguete / juguete terapéutico sea usado en el plano de asistencia de enfermería pediátrica.

Palabras clave:

Juegos y juguetes. Enfermería Pediatrica. Niño. Recreación. 


\section{INTRODUÇÃO}

A hospitalização traz transtornos em todas as fases da vida, que, particularmente na infância, são evidentes, com manifestações de insatisfação momentânea ou prejuízos que permanecem mesmo após a alta hospitalar. Na fase pré-escolar esses efeitos são mais intensos, independente da presença ou não da mãe, em virtude da etapa do desenvolvimento, onde a fantasia está presente em tudo 1 .

A hospitalização é também uma doença; assim, a criança que necessita ser hospitalizada encontra-se duplamente doente e, se não for tratada adequadamente, poderá sofrer danos em sua saúde mental?

Em virtude do seu pensamento fantasioso e egocêntrico, as crianças têm dificuldades na compreensão dos fatos e situações vivenciadas, podendo achar que a doença e/ou hospitalização é uma punição por mau comportamento ou algum erro. Aliado a isso, fatores culturais influenciam na forma como a criança percebe sua hospitalização. Assim, observamos, muitas vezes, procedimentos terapêuticos como injeções, administração de medicamentos e outros serem colocados às crianças como punição por mau comportamento ou erros de conduta ${ }^{3}$.

A rotina hospitalar contribui em muito para as dificuldades encontradas pelas crianças em vivenciar os dias de internação já que, muitas vezes, estão privadas da companhia materna, e as mudanças de funcionários a cada turno, que nem sempre estão fixos para o cuidado das mesmas crianças, dificultam ainda mais a formação de vínculo entre ambos. Esta situação é relacionada com a pobre experiência afetiva durante o período de internação. Os hospitais cuidam da doença, mas se esquecem da satisfação psicológica da pessoa adoecida. Dentre os prejuízos causados pela hospitalização infantil, as intervenções cirúrgicas e as moléstias crônicas em escolares são duas importantes situações nas quais as crianças vivenciam medo e culpa e tendem a se tornar muito dependentes da mãe e apresentar alterações no comportamento, como pavor noturno, negativismo, agressividade e dificuldade de relacionamento com outras pessoas. ${ }^{4}$.

Essas condições são encontradas em muitos de nossos hospitais, onde observamos uma valorização da doença em detrimento da qualidade de vida das crianças internadas. A instituição hospitalar sente-se comprometida com a eliminação da doença, mas não com a experiência subjetiva das pessoas com relação à vivência hospitalar, assim, observa-se uma preocupação em prolongar a vida biológica em detrimento de outras dimensões da vida 5 .

Estressores físicos e psicológicos decorrentes da hospitalização podem ser amenizados quando se permitem a permanência de uma pessoa significativa para a criança, a participação da própria criança no planejamento dos seus cuidados, a escolha dos alimentos e roupas preferidas, a continuidade das atividades escolares, a valorização do seu nome, as explicações, o apoio, a aceitação e a existência de um espaço para recreação $0^{6-8}$, ou seja, quando o cuidar está presente. Consideramos o cuidar em enfermagem não um ato que envolve apenas o domínio de técnicas e tecnologias, mas sim a complexidade do lidar com outro ser humano, sentir seu espírito, seu olhar, sua impotência, sua dor, suas revoltas e também suas alegrias 9 . Percebemos que em muitos hospitais isso não é levado em conta, observando-se, muitas vezes, entre os profissionais que lá atuam, justificativas como falta de tempo e que o reduzido número de profissionais para atender a uma demanda grande de crianças internadas faz com que deixem a atenção, o brincar, as explicações necessárias em segundo plano, embora considerem que isso seja importante para uma melhor atenção à criança e sua família.

Vários autores ressaltam que, usando o brinquedo como estratégia para diminuição do estresse provocado pela hospitalização e melhora no comportamento das crianças neste período, obtem-se um resultado positivo ${ }^{2,710-18}$. É importante salientar que, qualquer que seja a estratégia escolhida, ela deve estar adequada à fase de desenvolvimento da criança e entendimento da familia, possibilitando maior compreensão e, assim, contribuindo para o melhor enfrentamento da situação a que estão expostos.

A assistência à criança na atualidade baseia-se em algumas premissas que nem sempre estão presentes no cotidiano da enfermagem pediátrica, como: a criança está em processo de crescimento e desenvolvimento, com direitos e necessidades que precisam ser atendidas; portanto, devemos protegê-la e favorecer esse processo ${ }^{19}$.

Um fator essencial para o desenvolvimento da criança é, sem dúvida, o brincar. Ele está presente em todas as fases da vida e favorece, além da diversão, a expressão de sentimentos e emoções pelos quais o indivíduo passa.

Por intermédio do lúdico, a criança adquire novos conhecimentos em seu processo de desenvolver-se no mundo, descobre sua individualidade e conhece a realidade. Por meio da fantasia, consegue elaborar suas vivências, tanto as prazerosas quanto as difíceis. 0 brincar adquire, portanto, várias formas de contribuição para o desenvolvimento infantil.

No ambiente hospitalar, o brincar tende a transformar o ambiente das enfermarias em um local prazeroso e que permita uma adaptação melhor às novas condições que as crianças encontram e têm de enfrentar. São estratégias possíveis para o desenvolvimento de atividades lúdicas no hospital a apresentação e manipulação de equipamentos hospitalares e utilização de figuras representativas de situações às quais a criança será ou tenha sido submetida, possibilitando, pelo brincar, a elaboração das experiências, diminuindo a probabilidade do medo em relação a elas.

Existem dois tipos de brinquedo, o normativo e o terapêutico. Atividades espontâneas que levam ao prazer, sem no entanto precisar alcançar um objetivo, constituem 0 brinquedo normativo, e a sala de recreação é o melhor local para desenvolvê-lo. Já o brinquedo terapêutico necessita de um profissional para direcionar a criança. É necessário estimulá-la a participar, e o brinquedo tem como meta conduzir a criança, que vivencia uma situação atípica para sua idade, como por exemplo, a hospitalização, a um bem-estar físico e emocional. 0 ambiente deve ser previamente preparado com brinquedos, e existem técnicas espećficas para sua aplicaçãa ${ }^{13,20}$.

0 brinquedo terapêutico $(\mathrm{BT})$ fundamenta-se nas próprias funções do brinquedo, bem como na ludoterapia. É uma técnica que possibilita a dramatização de papéis, de conflitos, e a catarse, 
possibilitando a diminuição da ansiedade da criança. 0 brinquedo terapêutico pode ser utilizado por qualquer enfermeira, para qualquer criança e em qualquer local que seja conveniente para ambas; as sessões devem durar entre 15 e 45 minutos, e apenas as expressões verbais da criança podem ser refletidas a ela. Possibilitam à enfermeira identificar sentimentos e necessidades das crianças. Já a ludoterapia é uma técnica psiquiátrica, devendo ser utilizada apenas por esse profissional, por enfermeiras psiquiátricas ou por psicólogos; as sessões duram de meia a uma hora, é necessário um ambiente controlado, e as expressões verbais e nãoverbais são refletidas à criança ou interpretadas para ela. Éutilizada para crianças que apresentam distúrbios emocionais, neuróticos ou psicóticos e, geralmente, dura vários meses ${ }^{2,21}$. Acreditamos ser possível o desenvolvimento do BT pelos enfermeiros como forma de identificarem os sentimentos das crianças.

0 brinquedo terapêutico pode ser classificado em brinquedo dramático, brinquedo instrucional e brinquedo capacitador de funções fisiológicas. 0 brinquedo dramático é aquele no qual as crianças se utilizam de bonecos e materiais hospitalares para exteriorizarem seus sentimentos; por meio dele, podem reviver situações desagradáveis e dominá-las de uma forma que seja possível aceitá-las. Ele serve também para que os profissionais possam identificar o que está afligindo as crianças, para poderem intervir terapeuticamente e facilitar a comunicação entre criança e enfermeiro. Já o brinquedo instrucional é utilizado para a preparação da criança para a hospitalização e procedimentos e também pode ser usado como meio educativo. No planejamento dessa atividade, é importante levar em consideração a faixa etária da criança, e podem-se utilizar livros, brinquedos e equipamentos hospitalares. 0 brinquedo como capacitador de funções fisiológicas consiste em desenvolver atividades em que as crianças possam, de acordo com suas necessidades, manter ou melhorar suas condições físicas. São atividades terapêuticas por meio da brincadeira ${ }^{20}$.

Considerando a importância do brinquedo e da brincadeira para as crianças e os verdadeiros "traumas" pelos quais elas passam em uma situação de hospitalização, observamos o pouco uso desse recurso como estratégia de cuidado no hospital. Intrigadas com esse panorama, propomos identificar a produção acadêmica de enfermeiros brasileiros (teses e dissertações) sobre o tema brinquedo no hospital, caracterizando-a e analisando qualitativamente o conteúdo desses trabalhos.

\section{METODOLOGIA}

Este é um estudo analítico reflexivo da produção acadêmica brasileira sobre o uso do brinquedo no hospital pelos enfermeiros pediatras, em programas de pós-graduação strictu sensu.

As fontes de referência para o levantamento bibliográfico utilizadas neste estudo foram: Portal Capes (Coordenação de Aperfeiçoamento de Ensino de Nível Superior); Publicações do Cepen (Centro de Estudos e Pesquisas em Enfermagem); Base de dados Ibict (Instituto Brasileiro de Informação em Ciência e Tecnologia) e consultas às referências bibliográficas das teses/dissertações que iam sendo adquiridas.
As palavras-chave utilizadas para a busca foram: Brinquedo terapêutico, Criança hospitalizada, Cuidado, Enfermagem pediátrica, Brinquedo, Procedimentos terapêuticos, Jogos e brinquedos, Lúdico.

Estes descritores foram definidos a partir de uma busca no Nursing Index e nos descritores em Ciências da Saúde da Biblioteca Regional de Medicina (Bireme).

Utilizamos os descritores para encontrar os trabalhos pelos seus títulos e, em seguida, realizamos a leitura dos resumos quando disponíveis. Para adquirir as teses e dissertações, utilizamos o programa de comutação bibliográfica (Comut), buscas pessoais nas bibliotecas de origem e o contato pessoal com os autores.

Os critérios para inclusão dos textos na amostra foram teses ou dissertações, produzidos no Brasil por enfermeiros, nos quais o brinquedo tenha sido usado como recurso de cuidado em crianças no hospital.

A pesquisa foi realizada sem definição de um período de tempo, já que nossa intenção era conhecer toda a produção acadêmica dos enfermeiros sobre 0 assunto. Esta produção acadêmica se insere no período de 1974 (primeiro trabalho referenciado) a 2003 (época da realização deste estudo).

Após a definição das teses e dissertações que fariam parte do nosso estudo, as mesmas foram enumeradas em ordem crescente (n.01, n.02, n.03,...), conforme ordem alfabética dos autores (anexo).

É importante salientar que o trabalho n.11 (0 papel do brinquedo na aceleração do processo de recuperação e cura em enfermagem pediátrica, de Leda Santos Pires) foi o trabalho mais antigo (1974) encontrado, referenciado na dissertação de mestrado de Barreto ES (n.4); entretanto, não foi possível sua localização nem mesmo na biblioteca da instituição onde foi defendida, razão pela qual não foi analisado.

Depois de repetidas leituras, os textos foram agrupados em unidades temáticas ou núcleos de sentidos e submetidos à análise de conteúdo 22 .

Para melhor compreensão dos dados apresentados em nossos resultados, resolvemos agrupá-los quanto aos objetivos, situação em que o brinquedo foi utilizado, resultados obtidos pelos autores com a utilização do brinquedo e suas recomendações. Procuramos, assim, evidenciar os significados desses achados.

\section{ANÁLISE DO CONTEÚDO DAS TESES/ DISSERTAÇÕES}

Analisando os objetivos, notamos uma preocupação dos autores em desvendar o significado da vivência da criança perante a cirurgia, quer seja no pré ou no pós-operatório, sendo este o foco mais freqüente nos objetivos dos trabalhos.

Desenvolver uma metodologia de assistência de enfermagem com abordagem psicossocial da criança submetida à cirurgia cardíaca. (n.01)

Descrever e comparar as respostas comportamentais apresentadas pela criança na RPO antes, durante e após a realização da sessão de brinquedo terapêutico. (n.02) 
Compreender o significado das interações vivenciadas por meninos em idade pré-escolar no pós-operatório de postectomia. (n.07)

Outro foco de atenção das autoras nos objetivos foi em relação ao comportamento da criança, quer seja em relação às mudanças comportamentais, influência do brinquedo no comportamento, respostas comportamentais ou expectativas das crianças em relação à cirurgia.

Verificar a influência da utilização do brinquedo terapêutico, pela enfermeira, sobre o comportamento de crianças de 3 a 5 anos de idade, recém-hospitalizadas, no primeiro ou segundo dia após a internação. (n.12)

Discutir as expectativas dos escolares em relação à cirurgia durante as brincadeiras. (n.08)

Identificar as estratégias utilizadas pelo menino enquanto vivencia a experiência cirúrgica. (n.07)

Houve interesse, também, em verificar a influência da doença e da hospitalização na vida da criança, utilizando-se como recurso o brinquedo.

Investigar a influência do mundo social e familiar da criança asmática sobre a manifestação de sua doença. (n.06)

Desvelar o sentido de Ser-criança com câncer em tratamento ambulatorial, utilizando a brinquedoteca como possibilidade de favorecer a expressão, pela criança, de seu mundo cotidiano. (n.10)

Compreender o significado das interações vivenciadas por crianças pré-escolares hospitalizadas. (n.13)

Os trabalhos também objetivaram analisar as formas de comunicação da criança, favorecer as expressões verbais e nãoverbais, identificar os significados das expressões verbais bem como das manifestações simbólicas verbais.

Identificar o conteúdo e o significado das verbalizações expressas pela criança durante a sessão de brinquedo terapêutico. (n.02)

Analisar as formas de comunicação dos escolares em relação à intervenção cirúrgica através das brincadeiras. (n.08)

... desvelar o sentido de Ser-criança com câncer em tratamento ambulatorial, utilizando a brinquedoteca como possibilidade de favorecer a expressão, pela criança, de seu mundo cotidiano. (n.10)

Uma das dissertações apresentou como objetivo a compreensão do significado de um trabalho de recreação no ambiente hospitalar para crianças, acompanhantes e profissionais.

Compreender o significado do 'Trabalho da Alegria' para os sujeitos que dele participaram. (n.15)

Os trabalhos que não utilizaram o brinquedo na abordagem direta com a criança tiveram como objetivo principal olhar para o profissional que cuida da criança, qual o significado e a importância que ele atribui a esta atividade, bem como as dificuldades de se implantar e manter as atividades lúdicas.

Identificar o grau de importância atribuído pelos profissionais da equipe de saúde às atividades lúdicas na Unidade Pediátrica. (n.04)

Identificar alguns fatores que impedem o planejamento, execução e avaliação das atividades lúdicas na Unidade Pediátrica. (n.04)

Compreender o significado, para a enfermeira, do lúdico no cotidiano do cuidado proporcionado à criança hospitalizada. (n.05)

Em relação à situação na qual o brinquedo foi utilizado, percebemos uma valorização das situações pré e póscirúrgicas: os trabalhos n.01, n.03, n.08, n.09 e n.14 utilizaram o brinquedo no pré-operatório, e n.01, n.02, n.03 e n.07, no pós-operatório. Isso corrobora com publicações científicas de periódicos nacionais e internacionais, nos quais percebemos inúmeros trabalhos utilizando o brinquedo no preparo da criança no pré-operatório, ou mesmo com função de catarse, no pós-operatório 7,13,16,23-24.

Na hospitalização da criança, aparecem os trabalhos n.12, que utilizou o brinquedo no primeiro ou segundo dias de internação da criança, e n.15, que usou dramatização em peça teatral, desenvolvida por alunos, juntamente com atividades de preparação de uma festa junina no hospital. Nesta situação, este recurso tem aparecido com freqüência na literatura científica, na dramatização de procedimentos e também para a compreensão dos sentimentos das crianças 12,17-18,25-27.

Quanto à utilização de recursos lúdicos e arte, observamos outros trabalhos utilizando histórias, desenho e pintura bem como dramatização teatral, com finalidade terapêutica ${ }^{16,28-29}$, demonstrando, assim, que esse recurso pode e deve ser amplamente utilizado pelos enfermeiros que trabalham com crianças.

Os trabalhos n.06 e n.13 utilizaram o brinquedo para entrevistar a criança com a finalidade de coletar dados. Este fato também é observado na literatura ${ }^{27}$.

Em um dos trabalhos, o brinquedo foi utilizado em ambulatório, com crianças que tinham diagnóstico de algum tipo de câncer, em uma brinquedoteca criada especialmente para a coleta dos dados (n.10). A utilização do brinquedo em situação semelhante foi publicada recentemente, porém sem 0 uso da brinquedoteca ${ }^{30}$.

Ainda temos os trabalhos que não utilizaram o brinquedo, por terem sido os sujeitos os profissionais, e não as crianças (n.04 e n.05).

Ao passar para análise dos resultados das teses/dissertações, optamos por tentar apreender apenas aqueles resultados que estivessem diretamente relacionados com nosso objeto de estudo, o brinquedo. Além disso, para facilitar a compreensão dos mesmos, agrupamos os resultados de acordo com a situação em que 0 brinquedo foi utilizado; assim, foram analisados os trabalhos que utilizaram o brinquedo na hospitalização, no ambulatório, para coleta de dados, no pré e no pós-operatório, valendo-nos dessas situações para o entendimento dos efeitos causados pelo uso do brinquedo na criança. 
Os trabalhos que utilizaram o brinquedo no contexto da hospitalização das crianças (n.12, n.13, n.15) evidenciaram que o mesmo promoveu uma mudança no comportamento delas, que passaram a interagir mais com outras pessoas, verbalizar melhor suas satisfações e expressar medos e ansiedades, além de ter proporcionado um aumento das brincadeiras e alegria no ambiente hospitalar e possibilitar a catarse.

...as crianças do grupo experimental passam a apresentar maior número de movimentação relativa à realização de alguma ação com objetivo definido, com independência e iniciativa, demonstrando interação com as pessoas e o meio ambiente; mais respostas a um estímulo externo e maior participação na resolução de algum problema. (n.12)

Durante as sessões de brinquedo, as crianças dramatizaram intensa e repetidamente procedimentos comuns na hospitalização... essa persistente dramatização mostra o quanto a criança se sente ameaçada pelos procedimentos. (n.13)

....facilitou o relacionamento do pessoal do hospital entre si, com a criança e com o acompanhante. Isso facilitou a comunicação trazendo, conseqüentemente, uma maior participação de todos no tratamento.(n.15)

No ambulatório, o brinquedo apresentou função terapêutica, minimizando sinais e sintomas inicialmente apresentados pelas crianças. Foi facilitador na expressão dos sentimentos de crianças com diagnóstico de asma e câncer, proporcionando catarse, extravasamento de ansiedades, modificações no comportamento além de uma integração das crianças-famílias com as pesquisadoras.

... as crianças submetidas às sessões de brinquedo terapêutico dramático, todas evoluíram de modo satisfatório, tendo seu diagnóstico clínico sido substituído de asma grave para moderada. (n.06)

...enquanto a criança com câncer brincava, seus olhos passaram a enxergar perspectivas até então desconhecidas, tirando-a da condição passiva de doente e colocando-a ativamente colaboradora de seu tratamento. (n.10)

Os trabalhos que utilizaram brinquedo para a coleta de dados apontam que este recurso foi essencial e que, sem ele, teria sido impossível conseguir os dados relevantes ao seu trabalho dada a incapacidade que a criança em idade préescolar e escolar têm de se expressar por meio de palavras.

...as sessões de BTD... permitiram à criança e ao familiar: expressar seus sentimentos, fantasias, desejos e experiências vividas; exteriorizar as relações e papéis sociais internalizados por ela; comunicar-se eficazmente com o adulto; fazer crítica ao meio e às relações pessoais e familiares; passar de ser passivo para ativo; assumir papéis sociais "fazendo de conta" que é mãe, pai, profissional, etc.; promover a catarse e propiciar modificações no comportamento tal como implíito na concepção da técnica. Confirmou-se, assim, como um instrumento fundamental na coleta de dados... (n.06)

...foi "brincando de uma criança que está no hospital" que ela (criança) revelou quais situações eram particularmente difíceis de enfrentar durante a hospitalização e o quanto toda essa situação se apresentava como algo misterioso e aterrorizante. (n.13)

As situações de pré e pós-operatório foram analisadas conjuntamente, pois, naqueles trabalhos em que as autoras utilizaram as duas situações, a análise feita por elas utilizou 0 mesmo processo, sendo difícil identificar, muitas vezes, em qual situação se deu o fenômeno, se no pré ou no pós-operatório. Assim, evidenciou-se que as crianças, nestas situações, utilizaram o brinquedo como forma de comunicação, para reflexão, e para evidenciar seus medos, como forma de catarse. 0 brinquedo pôde proporcionar mudança no comportamento, além de facilitar a interação da pesquisadora com a criança e propiciar sua orientação.

...tal preparo (pré-operatório) serviu para desmistificar a intervenção cirúrgica a que seria submetida a criança e facilitou o acompanhamento de cada etapa do tratamento sem surpresas. (n.01)

A experiência com o preparo da criança para a cirurgia possibilitou-me fornecer, ao mesmo tempo, informações antecipadas à criança e a seus pais, aliviando a tensão e a ansiedade de ambos... (n.03)

...demonstram o quanto se sentem agredidos pelo procedimento cirúrgico propriamente dito... pelos objetos... pelas pessoas do hospital... (n.07)

Dos seis escolares entrevistados, três mencionaram o sentimento de medo em relação aos procedimentos invasivos, em especial as injeções... O medo da morte foi um sentimento evidenciado nas falas de dois escolares... (n.08)

As dissertações n.04 e n.05 foram analisadas separadamente, já que tratam da utilização do brinquedo por profissionais, e não no atendimento às crianças. Assim, observamos que, embora produzidos em épocas distintas, os resultados desses trabalhos aparecem de forma semelhante. Os enfermeiros reconhecem o lúdico como imprescindível no atendimento à criança embora o tecnicismo se mantenha presente nas atividades do dia-a-dia.

Embora a maioria dos profissionais tenha dado grau MI (muito importante) para a "satisfação da necessidade de recreação" da criança na Unidade de Pediatria, parece não existir um consenso entre os profissionais do que fazer para atender esta necessidade... (n.04)

As enfermeiras mostram que o lúdico é ponto relevante no que concerne ao cuidado prestado à criança, e que, muitas vezes, são coisas simples que fazem a diferença nesse encontro de cuidado entre duas pessoas. (n.05) 
Em 1979, no trabalho n.04, os enfermeiros entrevistados não reconheceram a pediatria como especialidade que daria aos profissionais conhecimentos para valorizar o planejamento e desenvolvimento da recreação na unidade de pediatria.

...enfermeiros e nutricionistas, que não reconheceram a Pediatria como uma especialização que daria aos profissionais o conhecimento científico para valorizar o planejamento e desenvolvimento da recreação na Unidade de Pediatria. (n.04)

Ainda nesse trabalho, era a recreadora a pessoa reconhecidamente capaz para desenvolver atividades lúdicas com as crianças; já, em 2001, como nos dias atuais, a enfermeira passou a atuar mais, utilizando estratégias lúdicas, embora ainda de forma bastante discreta.

... o serviço de recreação, segundo a legislação vigente, está afeto ao serviço social; a recreadora é a responsável pelo planejamento e execução da recreação nas Unidades de Pediatria... (n.04)

...percebe-se que as enfermeiras utilizam técnicas lúdicas ao lidar com a criança: o contato visual, o estímulo motor, sonoro e o toque, como espaço de troca. (n.05)

Quanto às dificuldades para a implementação de atividades lúdicas, os dois trabalhos apontam para a conscientização das pessoas e a falta de verbas para aquisição e manutenção dos brinquedos, o desaparecimento e dificuldades na desinfecção dos mesmos, bem como a rotina e a falta de tempo para realização das tarefas.

... as instituições não dispõem de verba para a compra de material para recreação, ficando sempre na dependência da compreensão dos administradores; dos donativos ou da iniciativa das recreadoras em organizar listas de doação. (n.04)

Desde a sua formação, a nível de graduação, trabalhase a parte técnica com maior afinco...o lúdico não é valorizado como deveria ser no cotidiano hospitalar e tampouco no universitário. (n.05)

O tecnicismo exigido nos dias atuais aparece nas observações realizadas no presente estudo, evidenciado pela falta de tempo para desenvolver 0 momento de cuidado humano, quando a importância deveria residir na interrelação entre enfermeira $e$ criança. (n.05)

Um fato que nos chamou a atenção é que, no trabalho n.04, a autora descreve que, embora os enfermeiros permanecessem 24 horas por dia junto da criança, a quase totalidade desconhecia como as atividades lúdicas ocorriam em sua instituição. Estas eram realizadas de forma restrita, discriminando as crianças que fariam uso da mesma. Ainda nesse trabalho, a autora observou que, das seis instituições que participaram do estudo, nenhuma delas apresentava qualquer atividade recreacional nas unidades de paciente externo.

Quanto às recomendações feitas em seus trabalhos, os autores salientam a importância de uma assistência voltada à criança e à família, na qual a identificação das necessidades da criança bem como de seus familiares sejam contempladas, 0 apoio emocional não seja negligenciado e o brinquedo seja utilizado neste contexto. Para isso recomendam:

Aos profissionais da saúde:

Aos profissionais que valorizem as necessidades de recreação nas 24 horas do dia, além de um planejamento visando às necessidades da criança. (n.04)

Atividades como a recreação, a ludoterapia, a brinquedoteca, entre outras sejam valorizadas $e$ envolvam todos que participam da assistência à criança hospitalizada. (n.15)

Exista continuidade nas atividades e que a enfermagem participe ativamente. (n.15)

Assistência holística à criança com asma grave, na qual sejam contemplados os aspectos físicos, emocionais, sociais e espirituais. (n.06)

Os profissionais da saúde sejam sensíveis para reconhecer quando a criança não está bem. (n.03)

Às instituições de ensino e hospitalares:

As instituições de ensino e hospitalares prepararem psicologicamente as crianças, prescrevendo o cuidado para cada caso individualmente. (n.01)

Um dos trabalhos recomenda maior atenção por parte das autoridades quer seja no intra ou no extra-hospitalar, a respeito da necessidade de recreação na unidade de internação pediátrica (n.04).

A valorização do desenvolvimento de pesquisas relacionadas à recreação e ao brinquedo na atenção à criança:

Às autoridades da área de saúde que façam cumprir as leis e realizem pesquisas relacionadas à recreação hospitalar. (n.04)

Enfermeiro deve realizar pesquisas nesta área. (n.12)

O BT como instrumento seguro para validar diagnósticos de enfermagem na área pediátrica. (n.02)

Realização de novos estudos sobre a mesma temática. (n.13)

Aos enfermeiros:

0 enfermeiro deve se preocupar com o cuidado emocional da criança hospitalizada. (n.12)

Ser o facilitador da experiência para a criança e seus pais. (n.13)

Oferecer informações e apoio aos pais, papel fundamental da enfermeira pediatra. (n.07)

O lúdico deve fazer parte da sistematização e da reflexão das enfermeiras. (n.05)

Construção de uma prática mais voltada para o mundo da criança e da família. (n.10) 
0 brinquedo seja utilizado como forma de comunicação, integração, diagnóstico e interação enfermeira-criança e pais-criança.

A recreação deve ser feita por todos os membros da equipe de saúde, principalmente pelo enfermeiro que deve utilizar o brinquedo como recurso diagnóstico e terapêutico durante a internação da criança. (n.04)

Utilização do brinquedo terapêutico no cuidado de enfermagem à criança hospitalizada. (n.12)

Manter os objetos de apego quando a mãe não está próxima da criança. (n.02)

A enfermagem pode utilizar como instrumento terapêutico atividades como correr, pular, cantar, rir, falar, contar histórias, entre outras espontâneas ou conduzidas. (n.15)

Os brinquedos sejam utilizados como forma de comunicação e orientação. (n.08)

Enfatizam a necessidade de capacitação dos enfermeiros para atuar holisticamente no cuidado à criança, bem como da utilização de recursos lúdicos.

Às escolas, que o ensino, a pesquisa e a capacitação para atuar com recreação sejam oferecidos nos cursos de graduação. (n.04)

Capacitação dos enfermeiros para que possam atuar holisticamente e trabalhar com o lúdico. (n.05)

E, ainda, reconhecem a importância e recomendam a permanência dos pais durante o maior tempo possível próximo à criança, mesmo em situações não habitualmente permitidas como na recuperação pós-anestésica (RPO) e na unidade de terapia intensiva.

\section{Referências}

1. Schmitz EM. A problemática da hospitalização infantil. In: Schmitz EM, organizadora. A enfermagem em pediatria e puericultura. São Paulo (SP): Atheneu; 1995.

2. Ribeiro CA. 0 efeito da utilização do brinquedo terapêutico, pela enfermeira pediatra, sobre o comportamento de crianças recémhospitalizadas [dissertação de mestrado]. São Paulo (SP): USP; 1986.

3. Whaley LF, Wong DL. Enfermagem pediátrica: elementos essenciais à intervenção efetiva. $5^{\text {a }}$ ed. Rio de Janeiro (RJ): Guanabara Koogan; 1999.

4. D’Andrea FF. Aspectos psicológicos da hospitalização infantil. Rev Bras Enferm 1962 out; 5: 417-23.

5. Ribeiro MJ. 0 atendimento à criança hospitalizada: um estudo sobre serviço recreativo-educacional em enfermaria pediátrica [dissertação de mestrado]. Campinas (SP):Ed da UNICAMP; 1993.

6. Rezende MA. 0 preparo da criança e do adolescente para enfrentar experiências difíceis. In: Sigaud CHS, Veríssimo MLOR, organizadores. Enfermagem pediátrica: 0 cuidado de enfermagem à criança e ao adolescente. São Paulo (SP): EPU; 1996.
Deve ser garantida a permanência da mãe junto à criança o maior tempo possível na RPO. (n.02)

Permitir e facilitar que a mãe exerça atividade terapêutica junto à criança. (n.13)

Após esta análise de trabalhos, segundo a qual os autores relatam os benefícios que o brinquedo proporcionou às crianças e seus pais, bem como a necessidade de que este recurso esteja presente no cuidado de enfermagem, e as dificuldades em utilizá-lo, podemos afirmar que 0 brinquedo tem papel fundamental no cuidado às crianças e é uma ferramenta indispensável e imprescindível para tornar este cuidado mais humanizado.

\section{CONSIDERAÇÕES FINAIS}

A necessidade do desenvolvimento da prática do brincar deve permear os cursos de graduação e pós-graduação lato e estrito senso, bem como os de nível técnico, possibilitando aos estudantes a capacitação necessária para o reconhecimento desta prática na assistência às crianças e desenvolvimento de habilidades para o seu uso. Isso deve ser tão valorizado como qualquer outro conhecimento científico ministrado nestes cursos, já que o consideramos como essencial para o desenvolvimento e bem-estar das crianças.

Reiteramos que o brincar deve ser considerado, pelo enfermeiro pediatra, a maneira mais adequada de se aproximar da criança, e possível de desenvolver uma empatia entre ambos, de ver e compreender o mundo com os olhos da criança e de estabelecer vínculos de amizade e amor entre enfermeira-criança-família.

Assim, recomendamos que a prática do brinquedo/ brinquedo terapêutico seja inserida no plano de assistência de enfermagem pediátrica.

7. Kikuchi EM, Tramontini CC, Lopes DFM, Kemmer LF, Garanhani ML. A criança cirúrgica e sua família: vivência de um projeto fascinante. Rev SOBECC 2000 jul/set; 5(3): 16-9.

8. Soares MRZ, Zamberlan MAT. A inclusão do brincar na hospitalização infantil. Estud Psicol, Campina, 2001 maio/ago; 18(2): 64-9.

9. Ferreira MA. As correntes teóricas e práticas das dimensões do cuidar na infância: abordagem introdutória ao tema. Esc Anna Nery Rev Enferm 2002 dez; 6(1): 75-8.

10. Ribeiro CA. 0 efeito da utilização do brinquedo terapêutico, pela enfermeira pediatra, sobre o comportamento de crianças recémhospitalizadas. Rev Esc Enf USP 1991 abr; 25(1): 41-60.

11. Ribeiro CA. 0 brinquedo terapêutico na assistência à criança hospitalizada: significado da experiência para o aluno de graduação em enfermagem. Rev Esc Enf USP 1998 abr; 32(1): 73-9.

12. Ribeiro CA. Crescendo com a presença protetora da mãe: a criança enfrentando o mistério e o terror da hospitalização [tese de doutorado]. São Paulo (SP): USP; 1999.

13. Pinheiro MCD, Lopes GT. A influência do brinquedo na humanização da assistência de enfermagem à criança hospitalizada. Rev Bras Enferm $1993 \mathrm{abr} / \mathrm{jun} ;$ 46(2): 117-31. 
14. Ziegler DB, Prior MM. Preparation for surgery and adjustment to hospitalization. Nurs clin North Am 1994 Dec; 29(4): 655-69.

15. Almeida FA, Angelo M. Brinquedo terapêutico: comportamentos manifestados por crianças em unidade de recuperação pós-operatória de cirurgia cardíaca. Rev Paul Enferm 2001 jan/abr; 20(1): 5-12.

16. Zahr LK. Terapeutic play for hospitalized preschoolers in Lebanon. Pediatric Nursing 1998 Sep/0ct; 23(5): 449-53.

17. Swinburne C. Bears with sore heads get to play. Nurs Times 1999 Nov; 95(46): 18.

18. Martins MR, Ribeiro CA, Borba RIH, Silva CV. Protocolo de preparo da criança pré-escolar para punção venosa, com utilização do brinquedo terapêutico. Rev Latino-Am Enfermagem 2001 mar; $9(2): 76-85$.

19. Ribeiro CA, Borba RIH. Crescimento e desenvolvimento da criança. In: Santos LES, organizadora. Creche e pré-escola: uma abordagem de saúde. São Paulo (SP): Artes Médicas; 2004.

20. Vessey JA, Mahon MM. Terapeutic play and the hospitalized child. J Pediatr Nurs 1990 Oct; 5(5): 328-33.

21. Ribeiro CA, Maia EBS, Sabatés AL, Borba RIH, Rezende MA, Amorim FA. Mesa redonda: 0 brinquedo e a assistência de enfermagem à criança. Enferm Atual 2002 nov/dez; 6-17.

22. Minayo MCS. 0 desafio do conhecimento: pesquisa qualitativa em saúde. $4^{a}$ ed. São Paulo (SP)/Rio de Janeiro (RJ): HUCITEC/ Abrasco; 1996.

23. Duarte ERM, Muller AM, Bruno SMA, Duarte ALS. A utilização do brinquedo na sala de recuperação: um recurso a mais para assistência de enfermagem à criança. Rev Bras Enferm 1987 jan/mar; 40(1).

24. Valladares ACA. Manejo arteterapêutico no pré-operatório em pediatria. Rev Eletrônica Enferm [periódico on line] 2004 jan/abr; [citado 12 out 2004]; 6(1): 110-5. Disponível em http://www.fen.ufg.br.
25. Ribeiro CA. Sentindo o valor das experiências significativas para a aprendizagem: relato de duas situações vividas com crianças hospitalizadas. Rev Esc Enf USP 1983; 17(3): 179-203.

26. Kuntz N, Adams JA, Zahr L, Killen R, Cameron K, Wasson H. Terapeutic play and bone marrow transplantation. J Pediatr Nurs 1996 Dec; 11(6): 359-67.

27. Macgrath $P$, Huff N. What is it?: Findings on preschoolers responses to play with medical equipament. Child care health dev 2001 Sep; 27(5): 451-62.

28. Françani GM, Zilioli D, Silva PRF, Santana RPM, Lima RAG. Prescrição do dia: infusão de alegria. Utilizando a arte como instrumento na assistência à criança hospitalizada. Rev Latino-Am Enfermagem 1998 dez; 6(5): 27-33.

29. Nogueira W, Masetti M. Os doutores da alegria; um relato de experiência. 0 mundo da saúde 2000 jul/ago; 24(4): 264-67.

30. Maia EBS, Guimarães RN, Ribeiro CA. 0 significado da medicação intratecal para a criança pré-escolar, expresso em sua brincadeira. Rev Paul Enferm 2003 set/dez; 22(3): 268-77.

\section{Sobre as Autoras}

Tânia Maria Coelho Leite

Faculdade de Ciências Médicas / Unicamp - Campinas (SP)

e-mail: tania@fcm.unicamp.br

\section{Antonieta Keiko Kakuda Shimo}

Faculdade de Ciências Médicas / Unicamp - Campinas (SP) 